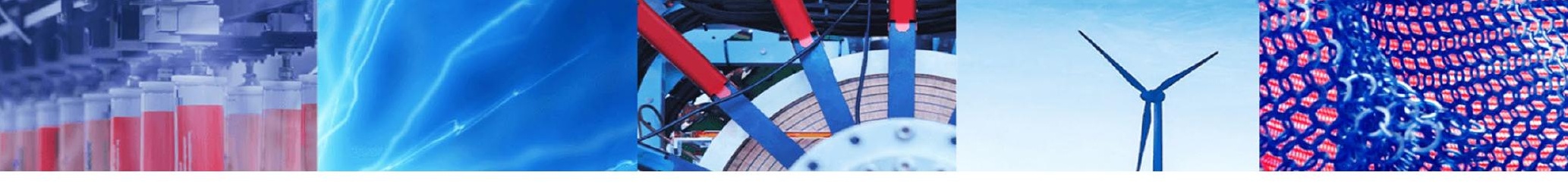

Research Article

\title{
Optimization of hydroxyapatite (HAp) extraction from scales of Sardinella longiceps and its conjugative effect with immunostimulants
}

\author{
A. Ashwitha ${ }^{1} \cdot$ K. Thamizharasan ${ }^{1} \cdot$ Prasanth Bhatt $^{1}$
}

Received: 19 March 2020 / Accepted: 11 June 2020 / Published online: 16 June 2020

(c) Springer Nature Switzerland AG 2020

\begin{abstract}
Hydroxyapatite $\left[\mathrm{Ca}_{10}(\mathrm{PO} 4)_{6}(\mathrm{OH})_{2}\right](\mathrm{HAp})$ has been regarded as a bone mineral, which acts as a grafting material due to its similar chemical composition with natural bones. HAp is thermodynamically stable at physiological pH and actively takes part in bone bonding. This property led has lead to HAp being widely used for rapid bone repair. HAp is derived from natural bio wastes such as fish scale which is the most definite standard source of both organic and inorganic constituents like collagen and hydroxyapatite. Titanium biomimetic method with the immersion of Stimulated Body Fluid solution were also used widely used for the precipitation of hydroxyapatite synthetically. Hence scales of Sardinella longiceps and titanium are chosen to be the essential source for the isolation of hydroxyapatite (HAp) in this current study. X-Ray Diffraction, Fourier-Transform Infrared spectrometry, Scanning Electron Microscopy confirms the phase, structural integrity and size of isolated HAp. Biocompatibility and calcium deposit assay with osteoblast cell line demonstrates the non-toxicity and efficiency of calcium deposits by HAp scales rather than synthetically derived Titanium mediated HAp. Hydroxyapatite can be doped with bactericidal silver nitrate and a biopolymer, bioadsorbable chitosan for the controlled release, targeted delivery, and corrosion resistance.
\end{abstract}

Keywords Sardinella longiceps scales · Hydroxyapatite (HAp) · Bone mineral · Biocompatibility · Calcium deposits

\section{Introduction}

The repair of damaged tissues is generally performed using autologous and allogenic grafts [1]. The most essential improvement in the tissue engineering, proposed the biomimetic processes through which natural biomaterials will be used to treat during loss of regenerative tissues or organ. Biomaterials actually interact with the organisms, mimics or improves the tissues and organs regeneration and also enhances their functions [2]. Particularly, biomaterials like hydroxyapatite induce osteointegration leading to bone repair or regeneration $[3,4]$.

Hydroxyapatite $\left[\mathrm{Ca}_{10}(\mathrm{PO} 4)_{6}(\mathrm{OH})_{2}\right]$ constitutes the mineral phase of calcified tissues, hence called a bioceramic [5,
6].This bioceramic has various dimensional characteristics like rods, spheres, fibrous, and as platelets based on the surfactants used for extraction [7]. HAp is derived from natural bio wastes such as fish bone and fish scales [8]. Fish waste is the most definite standard source of protein, unsaturated fatty acids, antioxidants and antimicrobial peptides, but these wastes especially scales were considered worthless, though it constitutes both organic and inorganic constituents like collagen and hydroxyapatite [9]. The elasmoid scales mainly consist of hydroxyapatite (mineral component), type I collagen (organic component) and water [10-12]. In this current study, elasmoid scales of Sardinella longiceps were chosen to be the essential source for the isolation of hydroxyapatite (HAp).

A. Ashwitha, sriashwitha@gmail.com | 'Department of Biotechnology, Faculty of Science and Humanities, SRM Institute of Science and Technology, Kattankulathur, Tamilnadu 603203, India. 
Over 18-30 million tons of fish wastes are generated worldwide per year. The actual biomass of wastes generated through fish industries weighs about $50 \%$. Among those, $4 \%$ are fish scales which are considered worthless [9]. As stated earlier, since these fish scales constitutes both organic and inorganic compounds like HAp and collagen the scientific world focused on extracting and characterizing the biopolymer collagen which has many industrial values. But in recent years the scientific research has focused on HAp for bone grafting and to determine its osteoconductivity. Hence this particular research focused on extracting and characterizing the optimized HAp. Extraction of any biologically active compounds from wastes plays a major role in today's economic world. Hence, HAp from the fish scales will definitely have economic value and will help in fisheries waste management.

The culture status of sardines is almost 3.27 million tons worldwide and on an average in India it ranges to 3.57 lakhs. Important species of sardines that contribute the total production are Sardinella longiceps (10.8\%), Sardina pilchardus (33.6\%). Among 3.57 lakhs of sardines, 2.56 lakhs of Indian oil sardines (Sardinella longiceps) are cultured [13]. The waste generation from sardines will be really high comparative to other fish sources by considering the culture condition. Hence this current study specifically focused on HAp extraction from Sardinella longiceps. This may help in production of bioceramic HAp in a sustainable and an eco-friendly approach.

The biomaterial's surface topography, chemistry and mechanical characteristics greatly involve in cell functions by triggering sequential molecular events at the cell-material interface: cell adhesion, migration, proliferation and differentiation [4]. In this study, we are trying to establish the structural character of HAp doped with silver nanoparticles and chitosan. We have also tried to establish the antibacterial activity of the above said combination of molecules.

\section{Methodology}

\subsection{Sample collection}

Sardinella longiceps (Sardine) were purchased from the local market of Kancheepuram district, Tamilnadu, India. The scales were peeled off and used for this current study.

\subsection{Hydroxyapatite isolation from fish scales}

Hydroxyapatite (HAp) was isolated from fish scales using thermal decomposition method, a biologically safe and highly productive process which can provide fine nanostructures by heating the complete volume of sample solution and efficient radiative energy transfer [14]. Briefly, the fish Sardinella longiceps scales were peeled off, washed with distilled water and $30 \mathrm{~g}$ of dried scales were subjected to deproteinization using $1 \mathrm{~N} \mathrm{HCl}$ and $1 \mathrm{~N} \mathrm{NaOH}$, respectively. The deproteinized scales were dried at $60^{\circ} \mathrm{C}$ for $1 \mathrm{~h}$ and finally calcined at different temperatures with gradual increment $\left(50,70,90,100\right.$, and $\left.120^{\circ} \mathrm{C}\right)$ for synthesizing HAp powder [8].

\subsection{Hydroxyapatite powder characterization}

The isolated Hydroxyapatite (HAp) powder was characterized for its structure and chemical composition by FTIR, XRD, SEM, TG-DTA analysis [9]. The thermal stability of isolated HAp powder was determined by Thermo Gravimetric and Differential Thermal Analysis (TG-DTA) using thermal analyzer (NETZSCH Jupiter STA 491) at temperature ranging from 30 to $1250^{\circ} \mathrm{C}$. The phase and purity of crystalline HAp was determined by X-ray diffractometer (PANalytical, 207756, Netherlands). FTIR analysis of calcined HAp powder was performed using FTIR spectrometer (SHIMADZU, Irtracer 100) for the structural confirmation. The average particle size of powder was observed using Field Emission Scanning Electron Microscope (FEl, Quanta 200).

\subsection{Titanium mediated synthesis of hydroxyapatite}

Titanium biomimetic method is generally used for Ti coating with HAp. Briefly, the commercial pure titanium (cp-Ti) grade 4 which was used a substrate and was treated with 5 $\mathrm{M} \mathrm{NaOH}$ and stored at $60^{\circ} \mathrm{C}$ for $24 \mathrm{~h}$ which produce active metal site precipitating hydroxyapatite. Then the substrate is heated at $600^{\circ} \mathrm{C}$ and cooled for $1 \mathrm{~h}$ resulting in release of hydrated phase and forms a stable layer of HAp. Then immersed sequentially in sodium silicate solution at $37^{\circ} \mathrm{C}$ for seven days and 1.5 Stimulated Body Fluid (SBF) solution ( $\mathrm{pH} 7$ ) for 7 days (Nucleation) which accelerates hydroxyapatite precipitation by increasing saturation.

\subsection{Optimization of hydroxyapatite}

\subsubsection{Extraction of chitosan and doping of $\mathrm{HAp}$ with $\mathrm{AgNo}_{3}$ and chitosan}

The fish scales of Sardinella longiceps were peeled off, washed and dried for 4 days. Subsequently, $20 \mathrm{~g}$ of dried scales were treated with $4 \% \mathrm{NaOH}$ and incubated for 1 day. The scales were then washed a number of times with distilled water which led to deproteinization of scales. Following which, of $4 \% \mathrm{HCL}$ was added and incubated at 37 ${ }^{\circ} \mathrm{C}$ for $12 \mathrm{~h}$ till demineralization occurs yielding chitin. After several washes with distilled water the chitin was incubated in a mixture of $1 \% \mathrm{KMnO}_{4}$ and $1 \%$ oxalic acid for 2 
h. Oxidized chitin was then incubated in $65 \% \mathrm{NaOH}$ for 3 days for the deacytylation to occur to form chitosan and further dried at $100^{\circ} \mathrm{C}[15]$.

HAp scales obtained during the above procedure was added with $10 \mathrm{ppm} \mathrm{AgNO}_{3}$ and $1 \%$ chitosan and left undisturbed for 5 seconds which leads to the combination consisting of $\mathrm{HAp}, \mathrm{AgNO}_{3}$ and Chitosan (CH) [2].

\subsection{Antibacterial activity of doped $\mathrm{HAp}-\mathrm{AgCH}$ against $E$. coli}

Muller hinton agar (Table 2) plates were swabbed with 100 $\mu$ l of $E$. coli after enriching them in the nutrient broth. Once the plates were dried aseptically, wells were made using a sterile gel puncture and $10 \mu \mathrm{l}$ of $\mathrm{HAp}-\mathrm{AgCH}$ dissolved in $\mathrm{HCl}$, positive control (Ampicillin) and negative control $(\mathrm{HCl})$ was poured into the respective wells. Then the plates were incubated for overnight at $37^{\circ} \mathrm{C}$. After $24 \mathrm{~h}$ of incubation, the zone of inhibition was measured and analyzed [16].

\section{Results and discussion}

\subsection{Hydroxyapatite powder characterization}

For long, HAp has been in contention for its bioceramic property, since its structural composition mimics the mineral phase of bones. It also possesses bone grafting property due to their osteoconductivity and biocompatibility [17]. Hence, this study was an attempt to isolate HAp scale and synthesize Ti-HAp and characterize the same in terms of phase purity, structural composition and size using X-ray diffraction analysis, FTIR spectrum and SEM images.

The XRD pattern of derived HAp powder from scales of Sardinella longiceps was determined using continuous scan type XRD. The diffraction pattern of HAp scale was then compared with standard $\mathrm{nHAp}$ (commercially available HAp), Ti-HAp, Chitosan and Doped HAp-AgCH (Fig. 1). The well-defined peak of high intensity at $31.84^{\circ}$ corresponding to the plane 100 at $2 \theta$ and also the standard plane of HAp was found to be $(100,101,200,002,211$, $202,301,130,131,113,203,222,132,321,004,240,241$, 502,323 , and 511 ) which proved the purity of crystalline HAp powder [8]. The highest peak intensity at $27.66^{\circ}$ corresponding to the plane almost to $100(99.76)$ at $2 \theta$ evaluated that the phase purity of Ti-HAp was low when compared to HAp scales and nHAp, though not significant. It was also observed that all the peaks having $100 \%$ intensity at that particular $2 \theta$ values were having an $n=1$, which provides information on the order of reflection. The degree of crystallinity of the samples analyzed using the XRD results show that, peaks having the highest intensity are the reflections of the only crystalline materials present

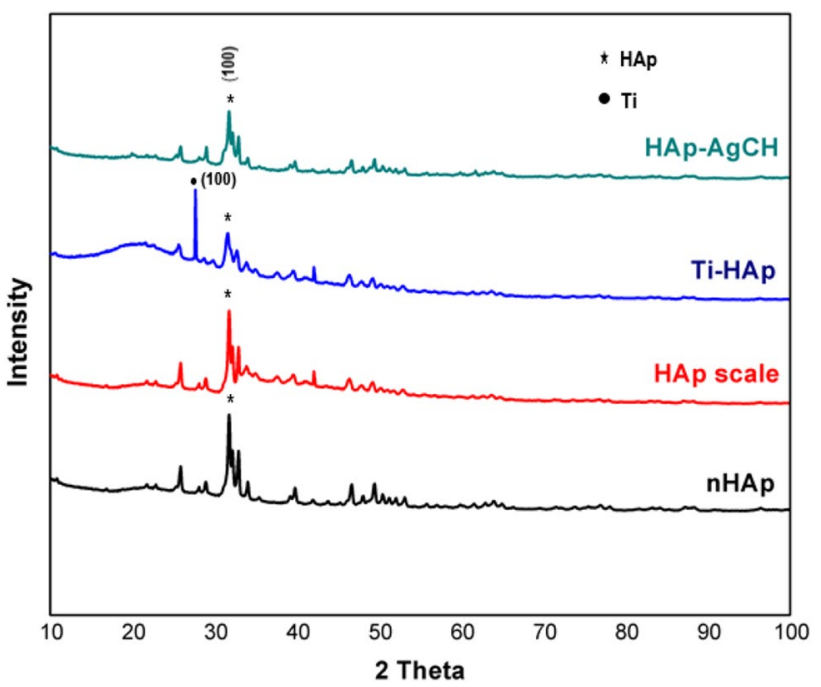

Fig. 1 X-ray diffraction pattern of nHAp, HAp scale, Ti-HAp, HAp$\mathrm{AgCH}$. The specific peak of HAp ( $\left.{ }^{*} \mathrm{HAp}\right)$ and $\mathrm{Ti}(\mathrm{Ti})$ at the plane (100) were represented

in the sample. Thus, the peak positions mentioned above have phase purity and are crystalline in nature.

The purity of a synthesized polysaccharide, namely chitosan was also interpreted for which the intensity was at $29.14^{\circ}$ at the plane 100 at $2 \theta$ which was similar to the previously reported research [18]. HAp scale was doped with the purified chitosan and silver nitrate. This doped $\mathrm{HAp}-\mathrm{AgCH}$ was then analyzed for its phase changes by $\mathrm{X}$-ray diffraction analysis. The peak intensity ranged at $31.77^{\circ}$ corresponding to the plane 100 at $2 \theta$. This shows that phase purity of HAp doesn't change when doped with immunostimulants like $\mathrm{Ag}$ and Chitosan. Unalloyed silver constitutes high electric, thermal conductivity and low contact resistance $[19,20]$. Ag derivatives has effective antimicrobial activity thus helping in therapeutic uses [21]. This antimicrobial property can be gained only through the ionization process in which the silver ion enters into the cell, interacts with the structural and enzymatic proteins resulting in the formation of insoluble products which is responsible for inhibiting the micro-organisms. Specifically, silver nitrate has been greatly involved in the clinical treatment of skin ulcer and bone fracture wherein it assists in wound healing [20].

Chitosan, a polymer has a wide range of applications in cartilage tissue engineering, wound healing and in bone regeneration [22]. It actively involves in delivering therapeutic drugs which accelerates bone growth releasing growth factors. This polymer of chitosan is stretchy but has low mechanical property compared to natural bones and is also non-osteoconductive in nature. But, when combined with biomaterials like HAp, alginate, poly-L-lactic acid and some growth factors it helps in effectively in 
bone development. This polymer when combined with ceramic materials like HAp induces mechanical strength and osteoconductivity $[23,24]$. Thus, this resulting combination ( $\mathrm{HAp}-\mathrm{AgCH}$ ) mimics both organic and inorganic components of bone and also greatly supports in bone regeneration.

The functional groups of fish scales HAp was determined and compared with standard nHAp, Ti-HAp, doped HAp-AgCH by FTIR spectroscopy (Fig. 2, Table 1). The spectrum was calculated in the range 4000-500 $\mathrm{cm}^{-1}$. In FTIR every individual peak of the spectrum

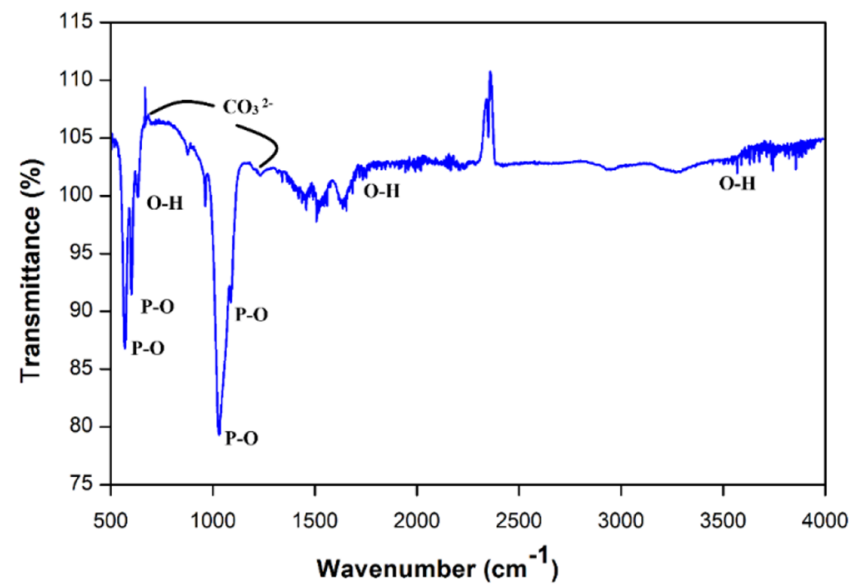

$\mathbf{a}$ defines the characteristic of HAp powder. The isolated $\mathrm{HAp}$ was confirmed by the definite clear peak at intensity $580.97 \mathrm{~cm}^{-1}$ which strongly corresponds to $\mathrm{PO}_{4}$ group. The bands at intensity between 943.80 and 1073.70 $\mathrm{cm}^{-1}$ also corresponds to the $\mathrm{PO}_{4}$ group which similar to the results observed by [8]. The bands at 873.23 $\mathrm{cm}^{-1}$ and between 1389.09 and $1589.9 \mathrm{~cm}^{-1}$ highly corresponds to adsorbed carbonated groups [9]. The clear peak at 1589.9 and the bands between 3055.96 and $3466.96 \mathrm{~cm}^{-1}$ determines the $\mathrm{OH}$ groups. The above obtained spectrum confirms the chemical composition

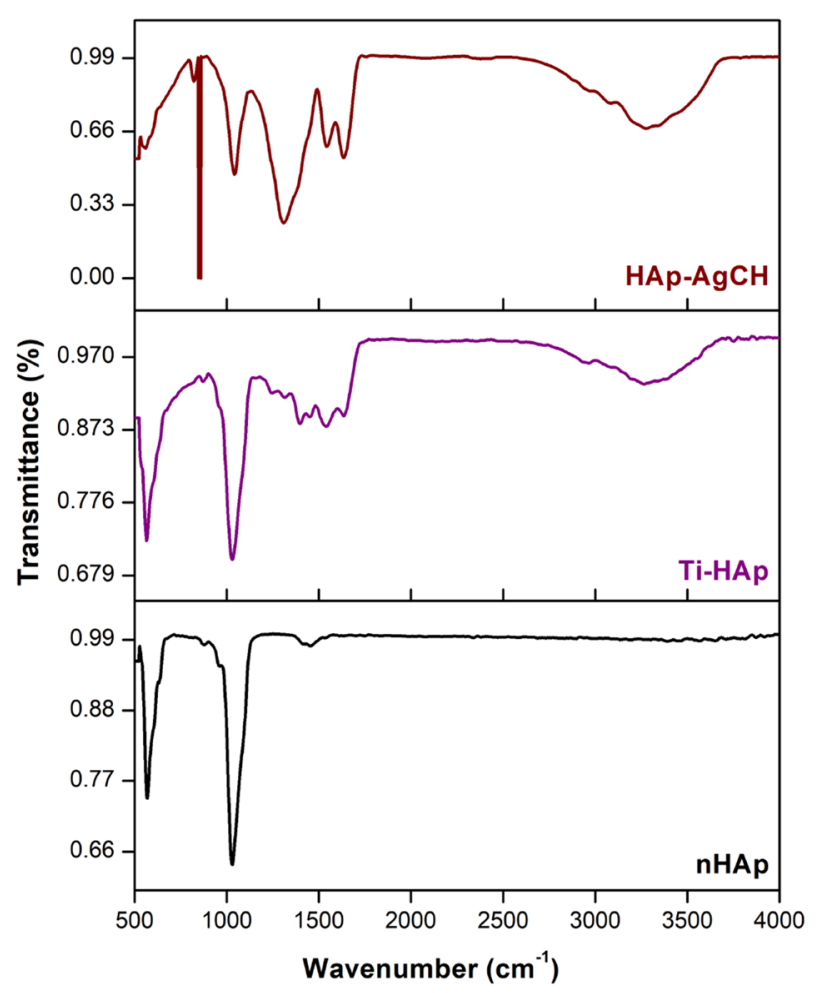

b

Fig. 2 FTIR spectrum, a HAp scale, b nHAp, Ti-HAp and $\mathrm{HAp}-\mathrm{AgCH}$

Table 1 FTIR spectrum analysis of nHAp, HAp scale, Ti-HAp, HAp-AgCH

\begin{tabular}{|c|c|c|c|c|c|c|c|c|}
\hline \multirow[t]{2}{*}{ Samples } & \multicolumn{8}{|c|}{ Position of bands $\left(\mathrm{cm}^{-1}\right)$} \\
\hline & $\mathrm{PO}_{4}{ }^{3-}$ & $\mathrm{CO}_{3}{ }^{2-}$ & $\mathrm{OH}$ & $\mathrm{CH}$ & $\mathrm{NH}$ & $\mathrm{CH}_{2}(\mathrm{C}=0)$ & $\mathrm{CN}$ & $\operatorname{COC}$ \\
\hline nHAp & $568.38,1030.07$ & 1453.62 & 3393.25 & - & - & - & - & - \\
\hline HAp scales & $\begin{array}{l}580.97,943.80- \\
1073.70\end{array}$ & $\begin{array}{l}873.23,1389.09- \\
1589.9\end{array}$ & $\begin{array}{c}1589.9 \\
3055.9- \\
3466.96\end{array}$ & - & - & - & - & - \\
\hline Ti-HAp & $565.93,1030.42$ & $871.63,1398.28$ & 3751.64 & - & - & - & - & - \\
\hline Chitosan & - & - & 3277.78 & $2986.33,2844.29$ & $1655.28,1592.94$ & 1405.42 & $\begin{array}{c}1331 \\
1321 \\
1260\end{array}$ & $811.20,1070.02$ \\
\hline $\mathrm{HAp}-\mathrm{AgCH}$ & 561.54 & $1543.31,1643.43$ & 3274.66 & 2849 & $1543.31,1634.43$ & 1309.23 & 1380 & 822.09 \\
\hline
\end{tabular}


of hydroxyapatite which was similar to the commercially available nHAp.

According to the spectra, Titanium mediated HAp (Ti$\mathrm{HAp}$ ) was identified by the absorption peaks of groups $\mathrm{PO}_{4}{ }^{3-}$ at intensity $565.93 \mathrm{~cm}^{-1}$ and $1030.42 \mathrm{~cm}^{-1}$, and $\mathrm{OH}$ at $3751.64 \mathrm{~cm}^{-1}$. The peaks at $871.63 \mathrm{~cm}^{-1}$ and 1398.28 $\mathrm{cm}^{-1}$ represents $\mathrm{CO}_{3}{ }^{2-}$. The wavenumbers of every functional group confirms HAp which was synthesized through precipitation of SBF solution. Significantly, the structural configuration of HAp and Ti-HAp are similar. Hence HAp scale can be an effective alternate to chemically synthesized HAp. But these Titanium alloys which is low biocompatible when coated with this effective bioceramic HAp provides accurate bonding with host bones [25].

The doped HAp (HAp-AgCH) was also determined by using Infrared spectrum. Briefly, the peaks at $3274.66 \mathrm{~cm}^{-1}$ determines the stretching $\mathrm{OH}$ group. The wavenumber 561.54 represents $\mathrm{PO}_{4}{ }^{3-}$, at $1543.31,1643.43$ corresponds to $\mathrm{CO}_{3}{ }^{2-}$, at $2849 \mathrm{~cm}^{-1}$ corresponds to the group $\mathrm{CH}$, the

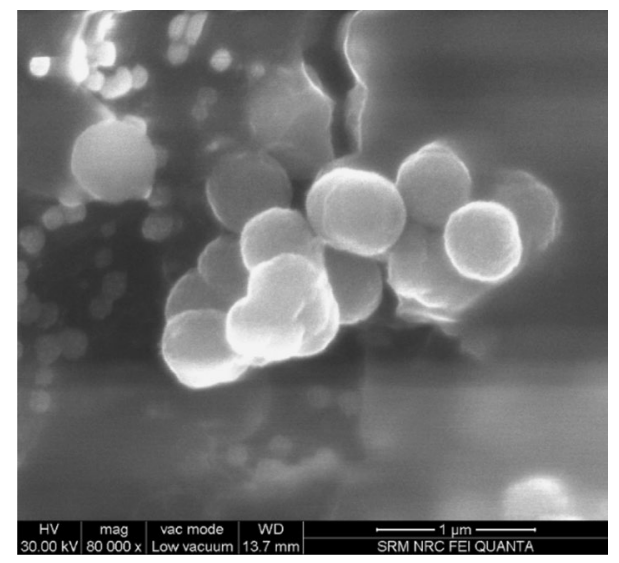

Fig. 3 SEM analysis of HAp scale peak at 1543.31 and $1634.43 \mathrm{~cm}^{-1}$ represents $\mathrm{NH}$ group. The wavenumber $1309.23 \mathrm{~cm}^{-1}$ represents $\mathrm{CH}_{2}$ peak at $1380 \mathrm{~cm}^{-1}$ represents $\mathrm{CN}$ group. The peak at $822.09 \mathrm{~cm}^{-1}$ corresponds to $\mathrm{COC}$ group.

The isolated HAp was present as soft agglomerates and the size of HAp was estimated to be $8 \mu \mathrm{m}$ (Fig. 3) and when HAp was doped with silver nitrate and $1 \%$ chitosan, $\mathrm{HAp}-\mathrm{AgCH}$ formed whole massive aggregates which was arranged as stacked plates which would be significant that the HAps would be absorbed easily by the osteoblast cells and helps in effective mineralization, as shape and size of nano-composites play a major role in tissue engineering (Fig. 4). The SEM analysis of HAp derived from fish scale shows the typical appearance of HAps [26]. Further, the spectrum obtained by EDS analysis determined the presence of calcium and phosphorus which confirms the presence of hydroxyapatite $\left[\mathrm{Ca}_{10}(\mathrm{PO} 4)_{6}(\mathrm{OH})\right]$ (Fig. 5, Fig. 6).

Thermo gravimetric (TGA) analysis disclosed the phase formation and evaluated the weight loss in the isolated HAp (Fig. 7). The weight loss of the scale was determined by heating between 50 and $1000{ }^{\circ} \mathrm{C}$. The weight loss was

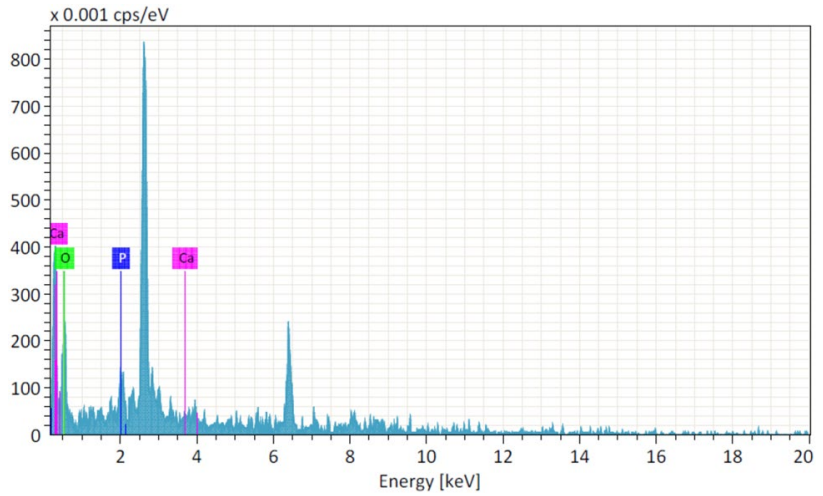

Fig. 5 EDS spectrum analysis of HAp
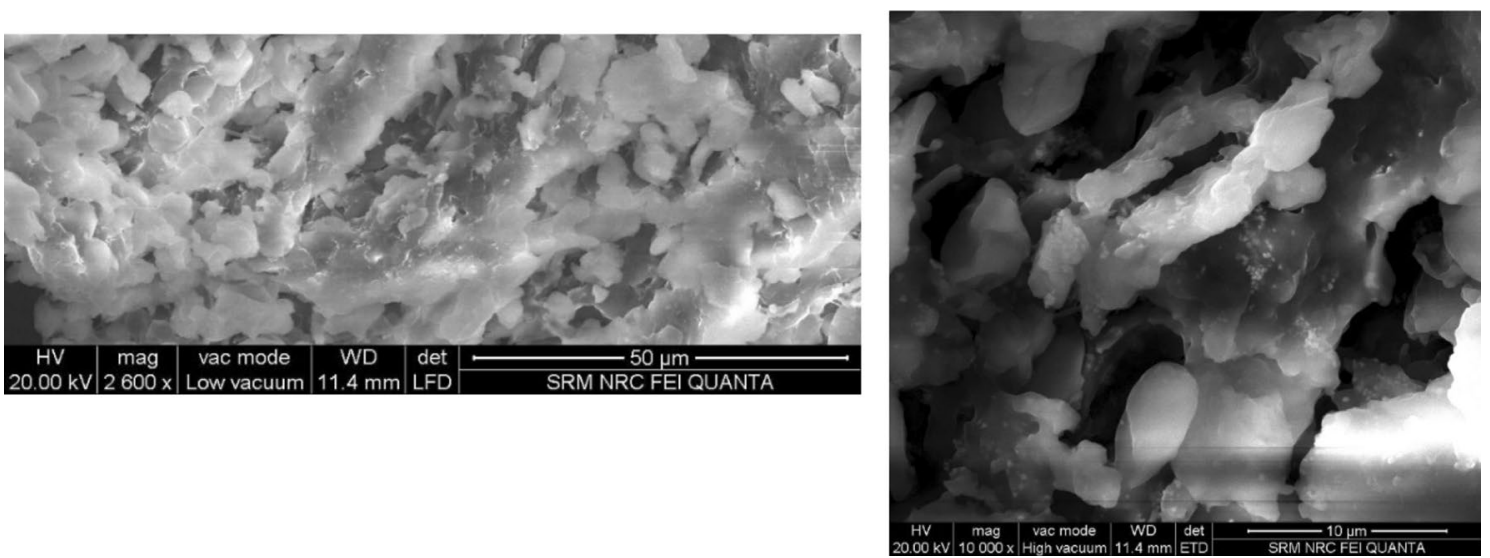

Fig. 4 SEM analysis of doped HAp-AgCH SEM analysis of doped HAp-AgCH 


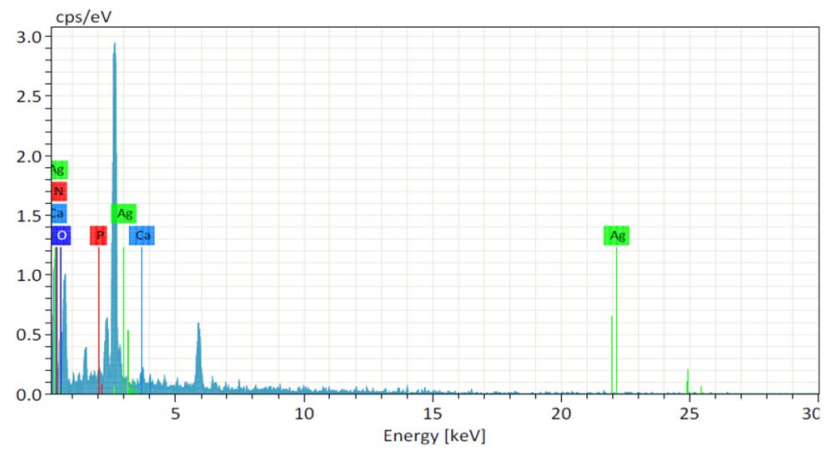

Fig. 6 EDS spectrum analysis of doped $\mathrm{HAp}-\mathrm{AgCH}$

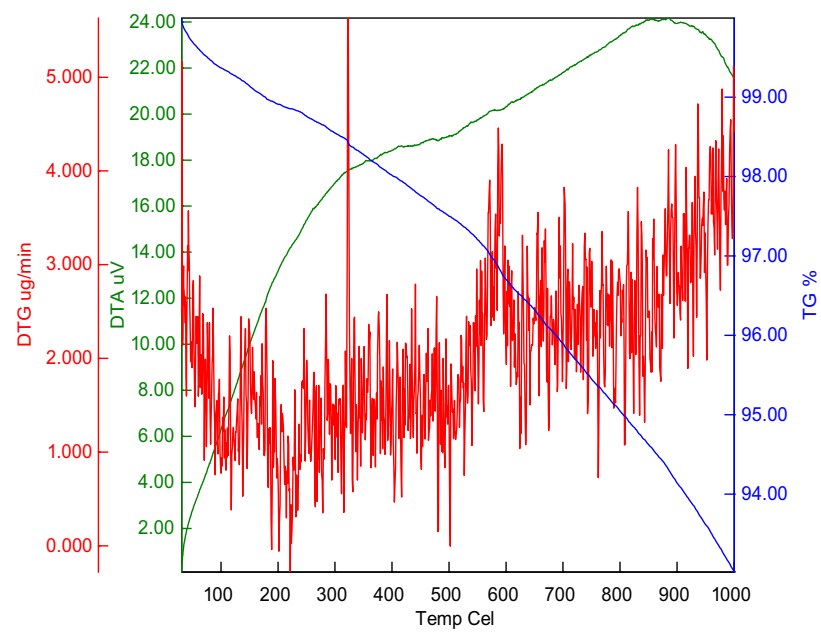

Fig. 7 TG/DTA analysis of isolated HAp

observed to be gradually decreasing between the temperature range of $50-400^{\circ} \mathrm{C}$, which can be attributed to the release of water molecules and formation of stable phase. The further decrease in weight of HAp can be attributed to the release or decomposition of organic matter in the scales of Sardinella longiceps, besides the release of water at $400-600^{\circ} \mathrm{C}$. Thermal treatment after $600-1000^{\circ} \mathrm{C}$ showed significant decrease in mass due to decarboxylation of $\mathrm{HAp}$ which releases $\mathrm{CO}_{2}$ and further $\mathrm{HPO}_{4}{ }^{2-}$ gets condensed forming stable phase. This revealed the overall thermal stability of isolated hydroxyapatite (HAp) at experimental range would be $600-1000^{\circ} \mathrm{C}$, which was similar to the results shown by previous researches $[8,14]$

Antibacterial activity of doped $\mathrm{HAp}-\mathrm{AgCH}$ was determined using well diffusion method as shown in the (Fig. 8, Tables 2, 3). The highest clear inhibitory zone of $\mathrm{HAp}-\mathrm{AgCH}$ at $12 \mathrm{~mm}$ compared to the positive control (Ampicillin) at $8 \mathrm{~mm}$ against E. coli and $22 \mathrm{~mm}$ (HAp$\mathrm{AgCH}$ ) compared to the positive control (Ampicillin) at $25 \mathrm{~mm}$ against Staphylococcus aureus confirmed the

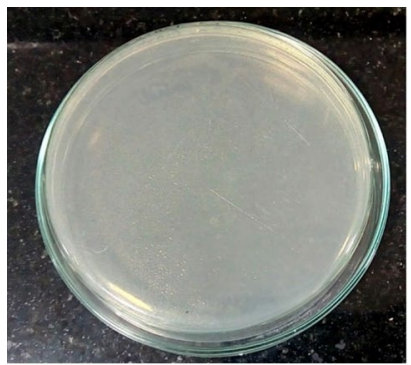

a

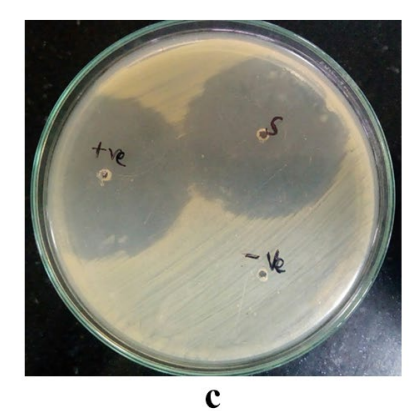

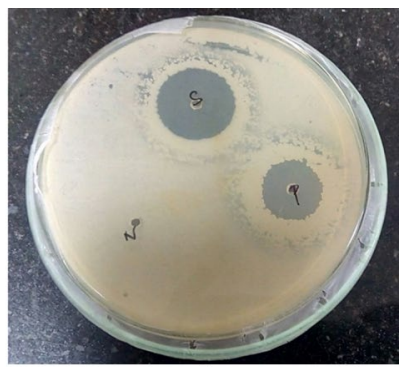

$\mathbf{b}$
Fig. 8 Antibacterial activity of doped $\mathrm{HAp}-\mathrm{AgCH}$, a control, b against $E$. coli, c against Staphylococcus aureus

Table 2 Zone of inhibition of doped HAp-AgCH against E. coli

\begin{tabular}{ll}
\hline Samples & $\begin{array}{l}\text { Zone of } \\
\text { inhibition } \\
(\mathrm{mm})\end{array}$ \\
\hline HAp-AgCH & 12 \\
+ve control (ampicillin) & 08 \\
-ve control (HAp) & $\mathrm{Nil}$ \\
\hline
\end{tabular}

Table 3 Zone of inhibition of doped HAp-AgCH against Staphylococcus aureus

\begin{tabular}{ll}
\hline Samples & $\begin{array}{l}\text { Zone of } \\
\text { inhibition } \\
(\mathrm{mm})\end{array}$ \\
\hline HAp-AgCH & 22 \\
+ve control (ampicillin) & 25 \\
-ve control (HAp) & $\mathrm{Nil}$ \\
\hline
\end{tabular}

effectiveness of $\mathrm{Ag}$ doped with $\mathrm{HAp}-\mathrm{CH}$ in killing the infectious pathogens. This effective inhibition of infectious pathogens by $\mathrm{HAp}-\mathrm{AgCH}$ is due to the doping of $\mathrm{Ag}$ which is actively responsible in killing both aerobic and anaerobic gram positive and gram negative bacteria. It also augments the activity of antibiotics like penicillin $\mathrm{G}$, kanamycin etc. when used in combination with it against bacterial infections [20]. 


\section{Conclusion}

From the study we were able to conclude that, the HAp from fish scale and Ti-HAp shared very similar physio-chemical characteristics. Thus, making fish scale a cost-effective alternative to Ti-HAp to be used during bone regeneration processes. Besides thermal stability evaluation of HAp extracted from fish scales exhibited at $600-1000^{\circ} \mathrm{C}$. This thermally stable, cost-effective bioceramic (HAp) on doping with $\mathrm{AgNO}_{3}$ and chitosan might help in augmenting the wound healing property and polymerizing activity respectively during bone repair, besides having a potent antibacterial activity. Further study on the invivo and invitro properties of the bioceramic extracted from an easily available and a cost effective source such as fish waste is necessary for determining its application in the tissue engineering of bone.

Acknowledgements We would like to acknowledge our first thanks to Dr. Venkatesh Kumaresan (Post-Doctoral Fellow, The University of Texas at San Antonio) for helping out in framing the good work. Special thanks to Dr. Nagaraj Selvamurugan (Professor, Department of Biotechnology, School of Bioengineering, SRM Institute of Science and Technology) for guiding us for the proper outcome of the work. A great thanks to Dr. Ashok. K. Sundramoorthy (Assistant professor, Chemical Sciences, SRM Research Institute, SRM Institute of Science and Technology) for providing us with their lab facilities., Dr. Karthikeyan Annamalai (Professor, Department of Physics and Nanotechnology, SRM Institute of Science and Technology) for doing TGDTA. Final thanks to Nanotechnology Research Centre and Department of Physics and Nanotechnology (SRM Institute of Science and Technology) for all the characterization techniques performed.

Author contributions AA: conceptualization, methodology, reviewing, writing-original draft preparation, software, editing. TK: conceptualization, methodology, visualization, investigation. PB: supervision, software, editing, data curation

Funding This research work was funded by the corresponding author.

Availability of data and materials Raw data for the research findings is available.

\section{Compliance with ethical standards}

Conflict of interest The authors declare that they have no conflict of interest

Ethics approval No work was performed which required ethical clearance in this study

Consent for publication We as authors give an informed consent to publish the data presented along with the article in your journal.

\section{References}

1. Venkatesan J, Lowe B, Manivasagan $\mathrm{P}$, Kang K-H, Chalisserry EP, Anil S, Kim DG, Kim S-K (2015) Isolation and characterization of nano-hydroxyapatite from salmon fish bone. Materials 8:54265439. https://doi.org/10.3390/ma8085253

2. de Sousa LL, Riccia VP, Pradoa DG, Apolinarioa RC, de Oliveira Vercikb LC, da Silva Rigob EC, dos Santos Fernandesc MC, Marianoa NA (2017) Titanium coating with hydroxyapatite and chitosan doped with silver nitrate. Mater Res 20(Suppl. 2):863-868. https://doi.org/10.1590/1980-5373-MR-2017-0021

3. Marcu T, Todea M, Maines L, Leordean D, Berce P, Popa C (2012) Metallurgical and mechanical characterisation of titanium based materials for endosseous applications obtained by selective laser melting. Powder Metall 55(4):309-314. https://doi. org/10.1179/1743290112Y.0000000007

4. Brie I-C, Soritaul O, Dirzu N, Berce C, Vulpoi A, Popa C, Todea $M$, Simon S, Perde-Schrepler M, Virag P, Barbos O, Chereches G, Berceand $P$, Cernea V (2014) Comparative in vitro study regarding the biocompatibility of titanium-base composites infiltrated with hydroxyapatite or silicatitanate. J Biol Eng 8:14. https://doi. org/10.1186/1754-1611-8-14

5. Fraga AF, de Almeida Filho E, da Silva Rigo EC, Boschi AO (2011) Synthesis of chitosan/hydroxyapatite membranes coated with hydroxycarbonate apatite for guided tissue regeneration purposes. Appl Surf Sci 257:3888-3892. https://doi.org/10.1016/j. apsusc.2010.11.104

6. Tripathi RM, Kumar N, Bhadwal AS, Gupta RK, Shrivastav BR, Shrivastav A (2015) Facile and rapid biomimetic approach for synthesis of HAp nanofibers and evaluation of their photocatalytic activity. Mater Lett 140:64-67. https://doi.org/10.1016/j. matlet.2014.10.149

7. Sanchez-Compos D, Mendoza-Anaya D, Reyes-Valderrama MI, Esteban-Gomez S, Rodriguez-Lugo V (2020) Cationic surfactant at high pH in microwave HAp synthesis. Mater Lett 265:127416. https://doi.org/10.1016/j.matlet.2020.127416

8. Mondal S, Mondal B, Dey A, Mukhopadhyay SS (2012) Studies on processing and characterization of hydroxyapatite biomaterials from different bio wastes. J Miner Mater Charact Eng 11(1):5567. https://doi.org/10.4236/jmmce.2012.111005

9. Huang Y-C, Hsiao P-C, Chai H-J (2011) Hydroxyapatite extracted from fish scale: effects on MG63 osteoblast-like cells. Ceram Int 37:1825-1831. https://doi.org/10.1016/j.ceramint.2011.01.018

10. Ikoma T, Kobayashi H, Tanaka J, Walsh D, Mann S (2003) Microstructure, mechanical, and biomimetic properties of fish scales from Pagrus major. J Struct Biol 142(3):327-333. https://doi. org/10.1016/S1047-8477(03)00053-4

11. Gil-Duran S, Arola D, Ossa EA (2016) Effect of chemical composition and microstructure on the mechanical behavior of fish scales from Megalops atlanticus. J Mech Behav Biomed Mater 56:134-145. https://doi.org/10.1016/j.jmbbm.2015.11.028

12. Whitehead PJP (1988) FAO species catalogue. Vol 7. Clupeiod fishes of the world (Suborder Clupeiodei). An annotated and illustrated catalogue of herrings, sardines, pilchards, sprats, shads, anchovies, wolf herrings. FAO Fisheries Synopsis, vol 125, no $7 / 1$, pp 1-303

13. Jayaprakash AA (2004) Trends in world sardine fisheries and India's status. Expo 2004 Central Marine Fisheries Research Institute, Kolkata

14. Meejo S, Maneeprakorn W, Winotai P (2006) Phase and stability of nanocrystalline hydroxyapatite via microwave heating. Thermochim Acta 447:115-120. https://doi.org/10.1016/j. tca.2006.04.013

15. Divya K, Rebello S, Jisha MS (2014) A simple and effective method for extraction of high purity chitosan from shrimp shell waste. In: Proceedings of the international conference on advances in applied science and environmental engineeringASEE 2014

16. Ashwitha A, Thamizharasan K, Vithya V, Karthik R, Vijaya Bharathi $S$ (2017) Effectiveness of bacteriocin from Bacillus subtilis 
(KY808492) and its application in biopreservation. J FisheriesSciences.com 11(3):036-042. https://doi.org/10.21767/1307234X.1000127

17. Itoh S, Kikuchi M, Kzuo Takakuda Y, Koyama HNM, Ichinose S, Tanaka J, Kawauchiand T, Shinomiya K (2001) The biocompatibility and osteoconductivity of novel hydroxyapatite/collagen composite biomaterial, and its function as carrier of rhBMP-2.J Biomed Mater Res 54(3):445-453. https://doi.org/10.1002/10974636(20010305)54:33.3.CO;2-0

18. Kumari S, Rath P, Sri Hari Kumar A, Tiwari TM (2015) Extraction and characterization of chitin and chitosan from fishery waste by chemical method. Environ Technol Innov 3:77-85. https:// doi.org/10.1016/j.eti.2015.01.002

19. Castellano JJ, Shafii SM, Ko F et al (2007) Comparative evaluation of silver-containing antimicrobial dressings and drugs. Int Wound J 4(2):114-122. https://doi.org/10.1111/j.1742481X.2007.00316X

20. Konop M, Damps T, Misicka A, Rudnicka L (2016) Certain aspects of silver and silver nanoparticles in wound care: a minireview. J Nanomater 26:1-10. https://doi.org/10.1155/2016/7614753

21. Ciobanu CS, Massuyeau F, Constantin LV, Predo D (2011) Structural and physical properties of antibacterial Ag-doped nanohydroxyapatite synthesized at $100^{\circ} \mathrm{C}$. Nanoscale Res Lett 6:613. https://doi.org/10.1186/1556-276X-6-613

22. El-Nahrawy AM, Ali Al, Abou Hammad AB, Youssef AM (2016) Influences of Ag-NPs doping chitosan/calcium silicate nanocomposites for optical and antibacterial activity. Int J Biol Macromol S0141-8130(16):31237-31245. https://doi. org/10.1016/j.ijbiomac.2016.08.045

23. Venkatesan J, Kim S-K (2010) Chitosan composites for bone tissue engineering -an overview. Mar Drugs 8:2252-2266. https ://doi.org/10.3390/md8082252

24. Mohammad NF, Othman R, Abdullah NA, Yeoh FY (2016) In vitro evaluation of mesoporous carbonated hydroxyapatite in MC3T3-E1 osteoblast cells. Procedia Chem 19:259-266. https ://doi.org/10.1016/j.proche.2016.03.103

25. Hekmatfar M, Moshayedi SH, Ghaffari SA, Rezaei HR, GolestaniFard F (2011) Fabrication of HAp-8YSZ composite layer on Ti/ $\mathrm{TiO}_{2}$ nanoporous substrate by EPD/MAO method. Mater Lett 65:3421-3423. https://doi.org/10.1016/j.matlet.2011.07.048

26. Santos MH, de Oliveira M, de Freitas Souza LP, Mansur HS, Vasconcelos WL (2004) Synthesis control and characterization of hydroxyapatite prepared by wet precipitation process. Mater Res 7(4):625-630. https://doi.org/10.1590/S1516-1439200400 0400017

Publisher's Note Springer Nature remains neutral with regard to jurisdictional claims in published maps and institutional affiliations. 